\title{
Colloid-Facilitated Transport of Radionuclides Through the Vadose Zone
}

\author{
Markus Flury \\ Department of Crop and Soil Sciences \\ Washington State University \\ Pullman, WA 99164
}

Given that there is a wide range of chemical compositions of Hanford Tank Waste, we have studied mineral formation and transformation by systematically varying anion composition and $\mathrm{OH}$ concentrations of simulated tank solutions in presence and absence of Cs. The feldspathoids and zeolite formed in the presence of Cs were analyzed with X-ray diffraction (XRD), Fourier transform infrared (FTIR) spectroscopy, scanning electron microscopy (SEM), and solid state NMR. The presence of Cs in the simulant solutions did not affect the types of minerals formed in $1 \mathrm{M} \mathrm{NaOH}$ solutions until the Cs concentration was greater than $0.1 \mathrm{M}$, a concentration that is not likely to occur in the sediment underlying the Hanford tanks. Elemental mapping indicated that incorporated Cs was homogeneously distributed in cancrinite and sodalite. High concentrations of Cs promoted the formation of highly crystalline cancrinite in hexagonal bar shape. The presence of Cs in solutions precluded the influence anions have shown in the non-cesium system. The presence of chloride anion was favorable for the formation of pure sodalite in a non-cesium solution, yet no sodalite has been found in the precipitates formed at high Cs concentration ( 0.5 M). Adsorption experiments indicated that Cs could access the internal parts of LTA, cancrinite and sodalite, but the diffusion appeared more difficult than that of $\mathrm{Na}$ and $\mathrm{K}$. Cesium exchange in cancrinite and sodalite caused structural disordering of the minerals as reflected by the XRD patterns. Incorporated and sorbed Cs showed 40 ppm chemical shifts on the 133Cs NMR patterns of LTA, indicating different chemical environments. Similar shifts were observed on cancrinite and sodalite lepispheres. We speculate that the adsorbed cesium was located in the larger cages of LTA zeolite, while the incorporated cesium is present in the smaller cages. Cesium could not migrate from one cage type to the other due to the large size of cesium ions. For the same reason, incorporated Cs could be easily replaced by other ions (e.g. Ca or K). Incorporating or adsorbing Cs did not distinctly shift the peak position or split the peak of 23Na NMR. This can be the result of the high motion of Na ions and water molecules inside the cages or channels which averages out the chemical environment of the ions. Hanford sediments were sampled in the ERDF pit between the 200E and 200W tank farms at Hanford. In two sampling campaigns in April and May 2003, we sampled three large undisturbed soil cores. The core sediments represent the two major sediment facies occurring in the Hanford formation: a coarse-pebbly sand and a finer-textured sand. The cores will be used for unsaturated transport experiments and are being prepared in the laboratory for setup. We are currently testing different porous materials as candidates to control the lower boundary conditions of the cores. Stainless steel membranes and fiberglass wicks seem to be the most promising materials so far, and detailed tests are conducted to examine colloid transmission through these materials. As soon as these tests are completed, we will finalize the column design and ship two of the columns to Tennessee, where John McCarthy will conduct the unsaturated transport experiments with the cores. One core will stay at Washington State University as backup. During the sampling at Hanford, plenty of disturbed sediment materials, and few smaller undisturbed cores were sampled for mineralogical and hydrological characterization of the sediments. This characterization work is currently ongoing. Colloid stability work, both in terms of mineral stability as well as colloid suspension stability, has been initiated. Native colloids isolated from Hanford sediments, colloids isolated after reaction of Hanford sediments with simulated tank waste, and reference clay minerals are tested for colloidal stability using three different methods: (1) batch flocculation series, (2) photon correlation spectroscopy, and (3) column mobilization experiments. Critical coagulation concentrations (CCC) are being determined for different electrolytes and sodium adsorption ratios (SAR). These studies will show whether colloids at Hanford can form stable suspensions in the pore water and how long suspensions stay stable. Saturated and unsaturated colloid and colloid-facilitated Cs transport experiments have been carried out under different degree of Cs loading on colloids. Experiments were done with 137Cs and we are using 22Na to determine Cs-Na selectivities in our columns. Results indicate the Cs movement can be facilitated by colloidal particles, but the quantitative amount of Cs that is moving with colloids is relatively small. Cesium is effectively stripped off form colloidal particles when colloids move through uncontaminated Hanford sediments, thereby limiting the amount of Cs that can be transported via colloids. Colloid mobility decreases with decreasing water saturation of the sediments. 
Nevertheless, at water saturations representative for natural Hanford sediments, a fraction of colloids remained mobile, indicating that colloidal movement and transport are possible in the Hanford vadose zone. Colloid-facilitated transport mechanisms are being incorporated into a geochemical transport code (FLOTRAN) and tested with the experimental data on colloid-facilitated Cs transport from the laboratory columns. FLOTRAN has been compared with analytical solutions of a two-region model (CXTFIT), and is currently adapted to include colloid-facilitated contaminant transport. 